\title{
One-year survival and admission to hospital for cardiovascular events among older residents of long-term care facilities who were prescribed intensive- and moderate-dose statins
}

\author{
Michael A. Campitelli MPH, Colleen J. Maxwell PhD, Laura C. Maclagan MSc, Dennis T. Ko MD MSc, \\ Chaim M. Bell MD PhD, Lianne Jeffs RN PhD, Andrew M. Morris MD SM, Kate L. Lapane PhD, \\ Nick Daneman MD MSc, Susan E. Bronskill PhD
}

Cite as: CMAJ 2019 January 14;191:E32-9. doi: 10.1503/cmaj.180853

See related article at www.cmaj.ca/lookup/doi/10.1503/cmaj.181671

\begin{abstract}
BACKGROUND: Guidance from randomized clinical trials about the ongoing benefits of statin therapies in residents of long-term care facilities is lacking. We sought to examine the effect of statin dose on 1-year survival and admission to hospital for cardiovascular events in this setting.
\end{abstract}

METHODS: We conducted a retrospective cohort study using population-based administrative data from Ontario, Canada. We identified 21808 residents in long-term care facilities who were 76 years of age and older and were prevalent statin users on the date of a full clinical assessment between April 2013 and March 2014, and categorized residents as intensive- or moderate-dose users. Treatment groups were matched on age, sex, admission to hospital for atherosclerotic cardiovascular disease, resident frailty and propensity score. Differences in 1-year survival and admission to hospital for cardiovascular events were measured using Cox proportional and subdistribution hazard models, respectively.

RESULTS: Using propensity-score matching, we included 4577 well-balanced pairs of residents who were taking intensiveand moderate-dose statins. After 1 year, there were 1210 (26.4\%) deaths and 524 $(11.5 \%)$ admissions to hospital for cardiovascular events among residents using moderate-dose statins compared with 1173 (25.6\%) deaths and 522 (11.4\%) admissions to hospital for cardiovascular events among those taking intensive-dose statins. We found no sig- nificant association between prevalent use of intensive-dose statins and 1-year survival (hazard ratio [HR] 0.97, 95\% confidence interval [Cl] 0.90 to 1.05 ) or 1-year admission to hospital for cardiovascular events (HR $0.99,95 \% \mathrm{Cl} 0.88$ to 1.12) compared with use of moderatedose statins.

INTERPRETATION: The rates of mortality and admission to hospital for cardiovascular events at 1 year were similar between residents in long-term care taking intensive-dose statins compared with those taking moderate-dose statins. This lack of benefit should be considered when prescribing statins to vulnerable residents of long-term care facilities who are at potentially increased risk of statin-related adverse events. tatins (hydroxymethylglutaryl-CoA reductase inhibitors) are used widely in persons of advanced age and in those living in long-term care facilities..$^{1,2}$ In Ontario, Canada, over one-third of all residents of long-term care facilities are prevalent statin users, including $28 \%$ of frail residents who have a limited likelihood of 1-year survival; nearly one-quarter of prevalent users received high doses. ${ }^{2}$ Historically, however, randomized clinical trials studying the efficacy and safety of statins rarely include adults aged 75 years and older, ${ }^{3}$ and most have not included residents of long-term care facilities. ${ }^{4}$ This leaves clinicians with little guidance when making ongoing decisions about treatment with statins, such as the appropriate dosing of statin medications, for patients in long-term care facilities and other populations of older adults. An observed threefold difference in the median proportion of residents in long-term care facilities receiving statins between high- and low-rate prescribers highlights the uncertainty faced by clinicians when making treatment decisions. ${ }^{2}$ 
Recent findings from a large observational cohort study suggested that prevalent use of high-intensity statins is associated with a greater reduction in 1-year mortality than moderateintensity statins, even among patients aged 76 years or older with atherosclerotic cardiovascular disease. ${ }^{5}$ However, residents of long-term care facilities are more likely to be frail and to have multiple physical and psychiatric comorbidities, resulting in a shorter life expectancy compared with community-dwelling older adults, which may alter the potential benefits of highintensity statin therapy. The Choosing Wisely campaign, which aims to reduce unnecessary medical treatments and intensity of therapy, states that, as individuals age, the adverse effects of using statins - including muscle symptoms, liver and kidney damage, falls and increased confusion - can potentially outweigh the benefits, particularly in those with no history of heart disease. ${ }^{6}$ An additional recommendation by Choosing Wisely Canada specific to the setting of long-term care is to stop longterm medications, such as high-dose statins, unless there is an appropriate indication and a reasonable expectation of benefit for the resident. ${ }^{7}$ Therefore, the objective of our study was to examine the rates of 1-year survival and admission to hospital for cardiovascular events among older residents of long-term care facilities who were prescribed intensive-dose statins compared with those receiving moderate-dose statins.

\section{Methods}

\section{Study design and setting}

We conducted a population-based retrospective cohort study involving residents of long-term care facilities in Ontario, Canada. The study used several health administrative and clinical assessment databases, which were linked using unique encoded identifiers and analyzed at ICES (Supplemental Table 1, Appendix 1, available at www.cmaj.ca/lookup/suppl/doi:10.1503/cmaj.180853/-/ DC1). Most of the cost of care in long-term care facilities is covered by the provincial health system, and all residents have access to physician services, hospital care and prescription medications.

\section{Study population}

The cohort creation, which has been described in detail elsewhere, ${ }^{2}$ used clinical data collected with the validated Resident Assessment Instrument-Minimum Data set version 2.0 (RAI-MDS 2.0) tool $^{8}$ linked with health administrative data.

The cohort comprised 76266 residents of long-term care facilities in Ontario who received a full clinical assessment between Apr. 1, 2013, and Mar. 31, 2014. We included those aged 76 years and older with recorded statin therapy (date dispensed plus days supplied) that overlapped or included the clinical assessment date. We extracted prescription medication claims for statins from the Ontario Drug Benefit database. We chose the restriction of 76 years and older because clinical trial evidence for statin use becomes sparse in this age category. ${ }^{9}$ The clinical assessment date served as the study index date.

Statin intensity was the exposure of interest. We used information on the statin drug claim overlapping the index date, including type of statin prescribed, quantity of pills provided and days of medication supplied, to calculate a resident's daily statin dose. We categorized residents who were prescribed atorvastatin (40 mg or more per day), rosuvastatin (20 mg or more per day) or simvastatin ( $80 \mathrm{mg}$ or more per day) as intensive-dose recipients. ${ }^{9}$ These dosage thresholds were selected because they were anticipated to achieve a $50 \%$ or more reduction in low-density lipoprotein cholesterol (LDL-C). ${ }^{9-11}$ All remaining statin users were categorized as moderate-dose recipients, including the small proportion $(<5 \%)$ receiving low-dose formulations, to be consistent with previous work. ${ }^{11}$

\section{Outcomes}

We followed all residents for 1 year after the index date for allcause mortality and admission to hospital for cardiovascular events. Date of death was ascertained using the Ontario Registered Persons Database, which contains vital statistics information for all Ontario residents enrolled in the provincial health system. We used the Canadian Institute for Health Information's Discharge Abstract Database, which compiles data on all inpatient admissions to acute care hospitals in Ontario, to ascertain admission to hospital for cardiovascular events (International Statistical Classification of Diseases and Related Health Problems, 10th revision code 100-199 as an admitting cause for the visit).

\section{Statistical analysis}

We identified important baseline characteristics associated with mortality and admission to hospital for cardiovascular events based on previous work by our team and others. ${ }^{2,12,13}$ Assessment items from the RAI-MDS 2.0 provided measures of clinical diagnoses, functional status and cognitive performance; they were also used to calculate a validated measure of resident frailty. ${ }^{14,15}$ This index of frailty covers many domains of health and is calculated as the proportion of accumulated to potential health deficits (from 72 RAI-MDS items) whereby those with greater than $30 \%$ of potential deficits are defined as frail. We used the Johns Hopkins Adjusted Clinical Groups ${ }^{\circledast}$ case-mix system (version 10.0) to compute the number of Aggregated Diagnosis Groups in the past 2 years as a general measure of comorbidity. ${ }^{16}$ We looked back 20 years from the index date to capture residents with a history of hospital admissions for atherosclerotic cardiovascular disease (admission for at least 1 of myocardial infarction, stroke, ischemic heart disease without infarction and peripheral arterial disease). ${ }^{9}$ History of hospital and emergency department use, overall and specifically for cardiovascular diagnoses, was captured in the year before the index date. Concurrent use of cardiovascular and other medications on the index date was obtained using the Ontario Drug Benefit database.

We compared residents with similar observed characteristics through propensity-score matching. We used a multivariable logistic regression model, including all resident characteristics and incorporating a random intercept specific to each long-term care facility to account for residents clustered within facilities, to compute an individual-level propensity score for receiving intensivedose statins compared with moderate-dose statins (Supplemental Table 2, Appendix 1). Residents taking intensive-dose statins were 
matched to those taking moderate doses based on propensity score ( \pm within 0.2 SDs of the score), age ( \pm within $1 \mathrm{yr}$ ), sex, previous admission to hospital for atherosclerotic cardiovascular disease and our indicator of resident frailty. ${ }^{14}$ We used standardized differences to compare resident characteristics before and after propensity-score matching, with a standardized difference of $10 \%$ or less representing adequate balance. ${ }^{17}$

In our analysis of all-cause mortality, we examined 1-year survival differences between the treatment groups by using Kaplan-Meier product-limit survival estimates and Cox proportional hazard modelling. For the outcome of admission to hospital for cardiovascular events, we compared the cumulative incidence of the first admission to hospital between treatment groups and used subdistribution hazard models to account for the competing risk of death because of the high mortality rate in the long-term care setting. ${ }^{18}$ All models used robust sandwichtype estimators to account for the matched nature of the data. ${ }^{19}$ Our analysis had $80 \%$ statistical power to detect an $11 \%$ relative difference in 1-year survival and a $16 \%$ relative difference in 1-year admission to hospital for cardiovascular events. In secondary analyses, the matched cohort was stratified by sex, previous admission to hospital for atherosclerotic cardiovascular disease and frailty status.

Independent of our cohort, we explored the proportion of residents in long-term care facilities aged 76 years and older who were prescribed a statin at some point between Apr. 1, 2013, and Mar. 31, 2014, and who were incident users (using a 1-yr look back to distinguish "new" use).

We conducted these analyses with SAS version 9.4. All statistical tests were 2-tailed, and we defined $p<0.05$ as the level of statistical significance.

\section{Ethics approval}

The use of data in this project was authorized under section 45 of Ontario's Personal Health Information Protection Act, which does not require review by a research ethics board.

\section{Results}

We identified 67208 residents of long-term care facilities aged 76 years and older between Apr. 1, 2013, and Mar. 31, 2014; 21808 were statin users on their index date, of which 4762 $(21.8 \%)$ received intensive-dose statins and 17046 (78.2\%) received moderate-dose statins. Atorvastatin was the most commonly prescribed statin medication among those taking intensive-dose (72.2\%) and moderate-dose (55.5\%) statins at the index date, and most (>99.5\%) had used statins the previous year, typically at the same dosage (Supplemental Table 3, Appendix 1). Of all the residents who were prescribed a statin at some point between Apr. 1, 2013, and Mar. 31, 2014, only $4.0 \%$ were considered incident users of the medication.

Before matching, residents taking intensive doses of statins were more likely to be younger, male, have a history of admission to hospital for atherosclerotic cardiovascular disease, 1 or more emergency department or hospital visits in the past year, and were concurrently using other cardiovascular medications, such as $\beta$-blockers and angiotensin-converting enzyme inhibitors, compared with those taking moderate doses (Table 1).

Propensity-score matching produced 4577 analytical pairs of residents taking intensive- and moderate-dose statins. The treatment groups were well-balanced as indicated by standardized differences that were less than $10 \%$ across all resident characteristics. After 1 year, there were 1210 (26.4\%) deaths and 524 (11.4\%) admissions to hospital for cardiovascular events among matched residents taking moderate doses compared with 1173 (25.6\%) deaths and 522 (11.4\%) admissions to hospital for cardiovascular events among those taking intensive doses.

One-year survival for matched residents taking intensive-and moderate-dose statins was $74.37 \%$ and $73.56 \%$, respectively (Table 2). The risk difference in 1-year survival between the treatment groups was not significant $(0.81 \%, 95 \%$ confidence interval [Cl] $-0.99 \%$ to $2.61 \%$ ). We found no significant association between 1-year survival and receiving intensive-dose versus moderate-dose statins (hazard ratio [HR] 0.97, 95\% Cl 0.90 to 1.05) using Cox proportional hazard modelling. Hazard ratios for mortality among males and females, residents with and without a previous admission to hospital for atherosclerotic cardiovascular disease, and residents who were frail and either prefrail or not frail were not significant.

The 1-year cumulative incidence of admission to hospital for cardiovascular events was $11.41 \%$ in residents taking intensivedose statins and $11.45 \%$ in those taking moderate doses, with a risk difference in outcomes of $-0.04 \%(95 \% \mathrm{Cl}-1.34 \%$ to $1.26 \%$; Table 3). We found no significant association between 1-year admission to hospital for cardiovascular events and use of intensive-dose statins compared with moderate-dose statins (HR 0.99, $95 \% \mathrm{Cl} 0.88$ to 1.12 ). We also observed nonsignificant associations in strata defined by sex, previous admission to hospital for atherosclerotic cardiovascular disease and frailty status.

\section{Interpretation}

In our population-based study of older residents of long-term care facilities in Ontario, just over $20 \%$ of all prevalent statin users were receiving intensive doses. After propensity-score matching, there was no significant association between the prescribed statin dose and 1-year survival or admission to hospital for cardiovascular events. This finding was consistent across subgroups of residents, including those with and without a previous admission to hospital for atherosclerotic cardiovascular disease, and among more robust residents with a lower baseline mortality rate.

For individuals with atherosclerotic cardiovascular disease who are 75 years of age and older, the guideline from the American College of Cardiology/American Heart Association Task Force on Practice Guidelines recommends moderate-intensity statins. ${ }^{9}$ Our findings are consistent with the guideline recommendations as most statin users were taking moderate doses, and the nonsignificant association between use of intensive-dose statins and our study outcomes highlights the possibility that the recommendation could be extended to older residents of long-term care facilities with and without atherosclerotic cardiovascular 
disease. However, a recent large observational study involving patients in the Veterans Affairs health care system in the United States found prevalent use of high-intensity statins to be associated with a statistically significant $9 \%$ decrease in 1-year mortality compared with moderate doses among adults older than
75 years with atherosclerotic cardiovascular disease. ${ }^{5}$ This result is contrary to our findings, and the discrepancy in results may be due to differences in the underlying study populations. Although the Veterans Affairs study followed all patients who were older than 75 years, we exclusively examined a cohort of residents of

Table 1 (part 1 of 2): Baseline characteristics of older Ontario residents living in long-term care facilities who were prescribed intensive- and moderate-dose statins between Apr. 1, 2013, and Mar. 31, 2014

\begin{tabular}{|c|c|c|c|c|c|c|}
\hline \multirow[b]{2}{*}{ Characteristic } & \multicolumn{3}{|c|}{ Unmatched residents } & \multicolumn{3}{|c|}{ Propensity-score matched residents } \\
\hline & $\begin{array}{c}\text { No. }(\%) \\
\text { taking } \\
\text { intensive- } \\
\text { dose statins } \\
n=4762\end{array}$ & $\begin{array}{c}\text { No. }(\%) \\
\text { taking } \\
\text { moderate- } \\
\text { dose statins } \\
n=17046\end{array}$ & $\begin{array}{l}\text { Standardized } \\
\text { difference }\end{array}$ & $\begin{array}{c}\text { No. }(\%) \\
\text { taking } \\
\text { intensive- } \\
\text { dose statins } \\
n=4577\end{array}$ & $\begin{array}{c}\text { No. }(\%) \\
\text { taking } \\
\text { moderate- } \\
\text { dose statins } \\
n=4577\end{array}$ & $\begin{array}{c}\text { Standardized } \\
\text { difference }\end{array}$ \\
\hline \multicolumn{7}{|l|}{ Demographic } \\
\hline \multicolumn{7}{|l|}{ Age group, yr } \\
\hline $76-85$ & $2624(55.1)$ & $7892(46.3)$ & 0.18 & $2505(54.7)$ & 2504 (54.7) & 0 \\
\hline$\geq 86$ & $2138(44.9)$ & $9154(53.7)$ & 0.18 & $2072(45.3)$ & $2073(45.3)$ & 0 \\
\hline Sex, male & $1903(40.0)$ & $5282(31.0)$ & 0.19 & $1801(39.3)$ & $1801(39.3)$ & 0 \\
\hline \multicolumn{7}{|l|}{ Time in long-term care facility, yr } \\
\hline$<1$ & $1656(34.8)$ & $4973(29.2)$ & 0.12 & $1552(33.9)$ & $1630(35.6)$ & 0.04 \\
\hline $1-4$ & $2443(51.3)$ & $8891(52.2)$ & 0.02 & $2376(51.9)$ & $2350(51.3)$ & 0.01 \\
\hline $5-9$ & $582(12.2)$ & $2798(16.4)$ & 0.12 & $568(12.4)$ & $518(11.3)$ & 0.03 \\
\hline$\geq 10$ & $81(1.7)$ & $384(2.3)$ & 0.04 & $81(1.8)$ & $79(1.7)$ & 0 \\
\hline \multicolumn{7}{|l|}{ General health status } \\
\hline \multicolumn{7}{|c|}{ Aggregated Diagnosis Groups in past 2 years } \\
\hline $0-5$ & $2653(55.7)$ & $11016(64.6)$ & 0.18 & $2596(56.7)$ & $2515(54.9)$ & 0.04 \\
\hline $6-10$ & $1514(31.8)$ & $4521(26.5)$ & 0.12 & $1428(31.2)$ & $1482(32.4)$ & 0.02 \\
\hline$\geq 11$ & $595(12.5)$ & $1509(8.9)$ & 0.12 & $553(12.1)$ & $580(12.7)$ & 0.03 \\
\hline \multicolumn{7}{|c|}{ Performance of activities of daily living } \\
\hline $\begin{array}{l}\text { Independent with or } \\
\text { without supervision }\end{array}$ & $472(9.9)$ & $1833(10.8)$ & 0.03 & $446(9.7)$ & $477(10.4)$ & 0.02 \\
\hline Limited & $536(11.3)$ & $1982(11.6)$ & 0.01 & $521(11.4)$ & $513(11.2)$ & 0.01 \\
\hline Extensive & $2476(52.0)$ & $8437(49.5)$ & 0.05 & $2378(52.0)$ & $2356(51.5)$ & 0.01 \\
\hline Dependent & $1278(26.8)$ & $4794(28.1)$ & 0.03 & $1232(26.9)$ & $1231(26.9)$ & 0 \\
\hline \multicolumn{7}{|l|}{ Cognitive performance scale } \\
\hline Intact or borderline intact & $1199(25.2)$ & $3977(23.3)$ & 0.04 & $1136(24.8)$ & $1161(25.4)$ & 0.01 \\
\hline Mild impairment & $965(20.3)$ & $3322(19.5)$ & 0.02 & $920(20.1)$ & $983(21.5)$ & 0.03 \\
\hline Moderate impairment & $2047(43.0)$ & $7272(42.7)$ & 0.01 & $1983(43.3)$ & $1931(42.2)$ & 0.02 \\
\hline Severe impairment & $551(11.6)$ & $2475(14.5)$ & 0.09 & $538(11.8)$ & $502(11.0)$ & 0.02 \\
\hline Frail participant* & $2543(53.4)$ & $9125(53.5)$ & 0 & $2458(53.7)$ & $2458(53.7)$ & 0 \\
\hline \multicolumn{7}{|l|}{ Clinical diagnosis } \\
\hline Diabetes & $2018(42.4)$ & $6516(38.2)$ & 0.08 & $1915(41.8)$ & $1915(41.8)$ & 0 \\
\hline Congestive heart failure & $911(19.1)$ & $2604(15.3)$ & 0.1 & $852(18.6)$ & $855(18.7)$ & 0 \\
\hline Hypertension & $3573(75.0)$ & $12693(74.5)$ & 0.01 & $3433(75.0)$ & $3450(75.4)$ & 0.01 \\
\hline Arteriosclerotic heart disease & $1267(26.6)$ & $3516(20.6)$ & 0.14 & $1181(25.8)$ & $1257(27.5)$ & 0.04 \\
\hline Peripheral vascular disease & $497(10.4)$ & $1245(7.3)$ & 0.11 & $457(10.0)$ & $451(9.9)$ & 0 \\
\hline Deep vein thrombosis & $50(1.0)$ & $223(1.3)$ & 0.02 & $49(1.1)$ & $46(1.0)$ & 0.01 \\
\hline Cardiac dysrhythmia disorders & $457(9.6)$ & $1493(8.8)$ & 0.03 & $438(9.6)$ & $432(9.4)$ & 0 \\
\hline
\end{tabular}


Table 1 (part 2 of 2): Baseline characteristics of older Ontario residents living in long-term care facilities who were prescribed intensive- and moderate-dose statins between Apr. 1, 2013, and Mar. 31, 2014

\begin{tabular}{|c|c|c|c|c|c|c|}
\hline \multirow[b]{2}{*}{ Characteristic } & \multicolumn{3}{|c|}{ Unmatched residents } & \multicolumn{3}{|c|}{ Propensity-score matched residents } \\
\hline & $\begin{array}{c}\text { No. (\%) } \\
\text { taking } \\
\text { intensive- } \\
\text { dose statins } \\
n=4762\end{array}$ & $\begin{array}{c}\text { No. }(\%) \\
\text { taking } \\
\text { moderate- } \\
\text { dose statins } \\
n=17046\end{array}$ & $\begin{array}{l}\text { Standardized } \\
\text { difference }\end{array}$ & $\begin{array}{c}\text { No. }(\%) \\
\text { taking } \\
\text { intensive- } \\
\text { dose statins } \\
n=4577\end{array}$ & $\begin{array}{c}\text { No. }(\%) \\
\text { taking } \\
\text { moderate- } \\
\text { dose statins } \\
n=4577\end{array}$ & $\begin{array}{l}\text { Standardized } \\
\text { difference }\end{array}$ \\
\hline $\begin{array}{l}\text { Alzheimer disease and related } \\
\text { dementias }\end{array}$ & $2751(57.8)$ & $10542(61.8)$ & 0.08 & $2667(58.3)$ & $2631(57.5)$ & 0.02 \\
\hline Cancer & $468(9.8)$ & $1486(8.7)$ & 0.04 & $438(9.6)$ & 439 (9.6) & 0 \\
\hline Emphysema/COPD/asthma & $994(20.9)$ & $3212(18.8)$ & 0.05 & $942(20.6)$ & $974(21.3)$ & 0.02 \\
\hline Depression & $1544(32.4)$ & $5475(32.1)$ & 0.01 & $1492(32.6)$ & 1459 (31.9) & 0.02 \\
\hline Arthritis & $58(1.2)$ & $226(1.3)$ & 0.01 & $57(1.2)$ & $52(1.1)$ & 0.01 \\
\hline Parkinson disease & $281(5.9)$ & $1146(6.7)$ & 0.03 & $271(5.9)$ & $239(5.2)$ & 0.03 \\
\hline \multicolumn{7}{|c|}{ History of atherosclerotic-related admission to hospital } \\
\hline Myocardial infarction & $1409(29.6)$ & $2549(15.0)$ & 0.36 & $1254(27.4)$ & $1381(30.2)$ & 0.06 \\
\hline $\begin{array}{l}\text { Ischemic heart disease } \\
\text { without infarction }\end{array}$ & $1631(34.3)$ & $3713(21.8)$ & 0.28 & $1494(32.6)$ & $1562(34.1)$ & 0.03 \\
\hline Stroke & $1569(32.9)$ & $3682(21.6)$ & 0.26 & $1464(32.0)$ & $1521(33.2)$ & 0.03 \\
\hline Peripheral arterial disease & $253(5.3)$ & $502(2.9)$ & 0.12 & $217(4.7)$ & $245(5.4)$ & 0.03 \\
\hline Any of the above* & $3185(66.9)$ & $7603(44.6)$ & 0.46 & $3017(65.9)$ & $3017(65.9)$ & 0 \\
\hline \multicolumn{7}{|c|}{ Emergency department and hospital use in past year } \\
\hline Any ED visit & $2609(54.8)$ & $8142(47.8)$ & 0.14 & $2461(53.8)$ & $2535(55.4)$ & 0.03 \\
\hline $\begin{array}{l}\text { Any inpatient admission to } \\
\text { hospital }\end{array}$ & $1860(39.1)$ & $5303(31.1)$ & 0.17 & $1734(37.9)$ & $1794(39.2)$ & 0.03 \\
\hline $\begin{array}{l}\text { Any ED visit with a } \\
\text { cardiovascular diagnosis }\end{array}$ & $612(12.9)$ & $1260(7.4)$ & 0.18 & $542(11.8)$ & $574(12.5)$ & 0.02 \\
\hline $\begin{array}{l}\text { Any inpatient admission to } \\
\text { hospital with a cardiovascular } \\
\text { diagnosis }\end{array}$ & $985(20.7)$ & $2154(12.6)$ & 0.22 & $878(19.2)$ & $953(20.8)$ & 0.04 \\
\hline \multicolumn{7}{|l|}{ Concurrent drug therapy use } \\
\hline \multicolumn{7}{|l|}{ No. of unique drug therapies } \\
\hline $0-5$ & $881(18.5)$ & $4035(23.7)$ & 0.13 & $862(18.8)$ & $849(18.5)$ & 0.01 \\
\hline $6-10$ & $2426(50.9)$ & $8797(51.6)$ & 0.01 & $2349(51.3)$ & $2310(50.5)$ & 0.02 \\
\hline$\geq 11$ & $1455(30.6)$ & $4214(24.7)$ & 0.13 & $1366(29.8)$ & $1418(31.0)$ & 0.02 \\
\hline $\begin{array}{l}\text { Angiotensin-converting } \\
\text { enzyme inhibitor }\end{array}$ & $1946(40.9)$ & $5941(34.9)$ & 0.12 & $1851(40.4)$ & $1877(41.0)$ & 0.01 \\
\hline Angiotensin receptor blocker & $714(15.0)$ & $2733(16.0)$ & 0.03 & $685(15.0)$ & $667(14.6)$ & 0.01 \\
\hline$\beta$-Blocker & $2273(47.7)$ & $6244(36.6)$ & 0.23 & $2137(46.7)$ & $2270(49.6)$ & 0.06 \\
\hline Calcium-channel blocker & $1572(33.0)$ & $5478(32.1)$ & 0.02 & $1498(32.7)$ & $1520(33.2)$ & 0.01 \\
\hline Oral antiglycemic & $1227(25.8)$ & $3962(23.2)$ & 0.06 & $1158(25.3)$ & $1159(25.3)$ & 0 \\
\hline Antipsychotic & $1223(25.7)$ & $4634(27.2)$ & 0.03 & $1182(25.8)$ & $1148(25.1)$ & 0.02 \\
\hline Benzodiazepine & $557(11.7)$ & 1985 (11.6) & 0 & $539(11.8)$ & $543(11.9)$ & 0 \\
\hline Antibiotic & $380(8.0)$ & $1220(7.2)$ & 0.03 & $354(7.7)$ & $353(7.7)$ & 0 \\
\hline Opioid & $922(19.4)$ & $3289(19.3)$ & 0 & $888(19.4)$ & $946(20.7)$ & 0.03 \\
\hline Antidepressant & $2431(51.0)$ & $8389(49.2)$ & 0.04 & $2339(51.1)$ & $2345(51.2)$ & 0 \\
\hline Cholinesterase inhibitor & $1324(27.8)$ & $5285(31.0)$ & 0.07 & $1296(28.3)$ & $1271(27.8)$ & 0.01 \\
\hline
\end{tabular}


Table 2: Association between statin dose and 1-year mortality in older Ontario residents living in long-term care facilities who were prescribed statins, overall and by subgroup*

\begin{tabular}{|c|c|c|c|c|c|}
\hline Analysis & $\begin{array}{l}\text { No. of matched } \\
\text { pairs analyzed }\end{array}$ & $\begin{array}{l}\text { One-year survival in } \\
\text { residents taking } \\
\text { intensive-dose } \\
\text { statins, \% }\end{array}$ & $\begin{array}{l}\text { One-year survival in } \\
\text { residents taking } \\
\text { moderate-dose statins, } \\
\%\end{array}$ & $\begin{array}{c}\text { Risk difference in } \\
\text { 1-year survival, } \\
\%(95 \% \mathrm{Cl})\end{array}$ & $\mathrm{HR} \dagger(95 \% \mathrm{CI})$ \\
\hline $\begin{array}{l}\text { Primary analysis, all } \\
\text { matched pairs }\end{array}$ & 4577 & 74.37 & 73.56 & $0.81(-0.99$ to 2.61$)$ & 0.97 (0.90 to 1.05$)$ \\
\hline \multicolumn{6}{|l|}{ Stratified analysis } \\
\hline \multicolumn{6}{|l|}{ Sex } \\
\hline Female & 2776 & 77.70 & 76.08 & $1.62(-0.60$ to 3.84$)$ & 0.93 (0.83 to 1.03$)$ \\
\hline Male & 1801 & 69.24 & 69.68 & $-0.44(-3.45$ to 2.57$)$ & 1.02 (0.91 to 1.15$)$ \\
\hline \multicolumn{6}{|c|}{ History of atherosclerotic-related admission to hospital } \\
\hline No & 1560 & 78.72 & 76.67 & $2.05(-0.88$ to 4.97$)$ & 0.91 (0.79 to 1.05 ) \\
\hline Yes & 3017 & 72.12 & 71.96 & $0.16(-2.11$ to 2.43$)$ & 1.00 (0.91 to 1.09$)$ \\
\hline \multicolumn{6}{|l|}{ Frailty status } \\
\hline Prefrail or not frail & 2119 & 82.77 & 83.48 & $-0.71(-2.97$ to 1.55$)$ & 1.05 (0.91 to 1.21 ) \\
\hline Frail & 2458 & 67.13 & 65.01 & $2.12(-0.53$ to 4.77$)$ & 0.93 (0.85 to 1.03 ) \\
\hline
\end{tabular}

Note: $\mathrm{Cl}=$ confidence interval, $\mathrm{HR}=$ hazard ratio.

*Statins prescribed between Apr. 1, 2013, and Mar. 31, 2014

tResidents taking moderate-dose statins served as the reference category.

Table 3: Association between statin dose and 1-year admission to hospital for cardiovascular events in older Ontario residents living in long-term care facilities who were prescribed statins, overall and by subgroup*

\begin{tabular}{|c|c|c|c|c|c|}
\hline \multirow[b]{2}{*}{ Analysis } & \multirow[b]{2}{*}{$\begin{array}{l}\text { No. of } \\
\text { matched pairs } \\
\text { analyzed }\end{array}$} & \multicolumn{2}{|c|}{$\begin{array}{c}\text { One-year cumulative incidence of } \\
\text { admission to hospital for cardiovascular } \\
\text { events, } \%\end{array}$} & \multirow[b]{2}{*}{$\begin{array}{l}\text { Risk difference in 1-yr } \\
\text { cumulative incidence, } \\
\qquad \%(95 \% \mathrm{Cl})\end{array}$} & \multirow[b]{2}{*}{ HR† $(95 \% \mathrm{Cl})$} \\
\hline & & $\begin{array}{l}\text { Residents taking } \\
\text { intensive-dose } \\
\text { statins }\end{array}$ & $\begin{array}{l}\text { Residents taking } \\
\text { moderate-dose } \\
\text { statins }\end{array}$ & & \\
\hline $\begin{array}{l}\text { Primary analysis, all } \\
\text { matched pairs }\end{array}$ & 4577 & 11.41 & 11.45 & $-0.04(-1.34$ to 1.26$)$ & 0.99 (0.88 to 1.12$)$ \\
\hline \multicolumn{6}{|l|}{ Stratified analysis } \\
\hline \multicolumn{6}{|l|}{ Sex } \\
\hline Female & 2776 & 10.34 & 10.77 & $-0.43(-2.05$ to 1.19$)$ & $0.96(0.82$ to 1.12$)$ \\
\hline Male & 1801 & 13.05 & 12.49 & $0.56(-1.62$ to 2.74$)$ & 1.04 (0.87 to 1.25$)$ \\
\hline \multicolumn{6}{|c|}{ History of atherosclerotic-related admission to hospital } \\
\hline No & 1560 & 8.08 & 8.21 & $-0.13(-2.06$ to 1.80$)$ & 0.98 (0.77 to 1.25$)$ \\
\hline Yes & 3017 & 13.13 & 13.13 & $0.00(-1.69$ to 1.69$)$ & $1.00(0.87$ to 1.15$)$ \\
\hline \multicolumn{6}{|l|}{ Frailty status } \\
\hline Prefrail or not frail & 2119 & 12.13 & 12.41 & $-0.28(-2.26$ to 1.70$)$ & $0.98(0.82$ to 1.16$)$ \\
\hline Frail & 2458 & 10.78 & 10.62 & $0.16(-1.57$ to 1.89$)$ & $1.01(0.85$ to 1.20$)$ \\
\hline
\end{tabular}


long-term care facilities with a high prevalence of frailty, functional limitations and cognitive impairment. Recent data suggest that traditional cardiovascular risk factors, such as LDL-C, are not significantly associated with mortality among individuals aged 80 years and older who are frail. ${ }^{20}$ Therefore, the use of intensive-dose statins to drive greater decreases in LDL-C may not have an effect on overall mortality for residents of long-term care facilities who frequently experience frailty and have a shorter life expectancy.

Intensive statin therapy is typically well-tolerated in older patients. ${ }^{21}$ However, the risks of statin-associated muscle symptoms, acute kidney injury and moderate or serious liver dysfunction are all heightened by increased statin doses.22-24 Also, clinically significant drug-drug interactions with statins are more common when a higher dose statin is used. ${ }^{25}$ While the incidence of serious adverse events from high-intensity statins has been reported to be low in community-dwelling older adults, these studies have typically not included residents of long-term care facilities who are at a higher risk for adverse drug effects and drug interactions because of their vulnerability and high rate of polypharmacy. ${ }^{26}$ This is an area in need of further research.

Our study mainly examined prevalent users of intensive- and moderate-dose statins rather than employing an incident-user design. ${ }^{27}$ However, we found that only $4.0 \%$ of residents in longterm care facilities who were prescribed a statin at some point during the study year represented incident users. Therefore, in this setting, it may be especially relevant to examine the benefits and risks of ongoing statin use. For this vulnerable older population with relatively high levels of frailty, cognitive and functional impairment, and limited life expectancy, special considerations are required to ensure that decisions regarding continued pharmacotherapy follow the principles of resident-centred care, which aim to maximize quality of life and reduce nonbeneficial treatments..$^{28-30}$

Given the lack of benefit we observed for ongoing use of intensive-dose statins compared with moderate-dose statins, a reduction in dose may be warranted among residents of long-term care facilities, particularly in those where the risk of statin-related adverse events would be expected to be relatively higher. However, these results may not be applicable to community-dwelling older adults who are taking statins. A recent primary care database study involving adults without atherosclerotic cardiovascular disease who were aged 75 years and older showed that new statin use was only associated with a significant reduction in atherosclerotic cardiovascular disease incidence and all-cause mortality among people aged $75-84$ years with diabetes; this benefit disappeared among those aged 85 years and older. ${ }^{31}$ In our study, given the care setting and focus toward ongoing use, we hypothesized that residents nearing death would be preferentially discontinued from statins, thus creating intractable bias in a comparison of residents currently taking statins and those not taking statins.

\section{Limitations}

Given the observational study design and use of administrative data, we cannot rule out residual confounding as an explanation for our results. To account for confounding bias, we used propensity-score matching to compare similar treatment groups and used rich, clinical assessment data to measure characteristics, such as physical and cognitive functioning, which are not typically available in traditional studies using administrative data. However, laboratory measures of cholesterol and other subclinical measures of cardiovascular functioning were not available. In addition, we lacked the necessary data for a comprehensive assessment of statin-related harms between different dosages. Finally, our study only provides evidence for the use of intensive-dose statins compared with moderate-dose statins in long-term care facilities, and we made no comparisons to a group of residents who were not taking statins.

\section{Conclusion}

There was no significant difference in 1-year outcomes among residents of long-term care facilities who were taking intensivedose statins compared with those taking moderate-dose statins in our population-based cohort. It may be prudent to reduce statin doses for specific vulnerable residents who are at increased risk of statin-related adverse events. Future research and clinical trials should focus on evaluating the efficacy and safety of statin use and dosing, as well as stopping the use of statins, in residents of long-term care facilities to help inform clinical practice.

\section{References}

1. Johansen ME, Green LA. Statin use in very elderly individuals, 1999-2012. JAMA Intern Med 2015;175:1715-6.

2. Campitelli MA, Maxwell CJ, Giannakeas V, et al. The variation of statin use among nursing home residents and physicians: a cross-sectional analysis. J Am Geriatr Soc 2017;65:2044-51.

3. Bourgeois FT, Orenstein L, Ballakur S, et al. Exclusion of elderly people from randomized clinical trials of drugs for ischemic heart disease. J Am Geriatr Soc 2017;65:2354-61.

4. Rich MW, Chyun DA, Skolnick AH, et al.; American Heart Association Older Populations Committee of the Council on Clinical Cardiology, Council on Cardiovascular and Stroke Nursing, Council on Cardiovascular Surgery and Anesthesia, and Stroke Council; American College of Cardiology; American Geriatrics Society. Knowledge gaps in cardiovascular care of the older adult population: a scientific statement from the American Heart Association, American College of Cardiology, and American Geriatrics Society. Circulation 2016;133:2103-22.

5. Rodriguez F, Maron DJ, Knowles JW, et al. Association between intensity of statin therapy and mortality in patients with atherosclerotic cardiovascular disease. JAMA Cardiol 2017;2:47-54

6. Cholesterol drugs for people 75 and older: when you need them - and when you don't. Philadelphia: Consumer Reports; 2017. Available: www.choosingwisely. org/patient-resources/cholesterol-drugs-for-people-75-and-older/ (accessed 2018 Jan. 22).

7. Long Term Care Medical Directors Association of Canada. Long-term care - Six things physicians and patients should question. Choosing Wisely Canada; updated 2017 Jan. 8. Available: https://choosingwiselycanada.org/long-term -care/ (accessed 2018 May 30).

8. Hirdes JP, Poss JW, Caldarelli $\mathrm{H}$, et al. An evaluation of data quality in Canada's Continuing Care Reporting System (CCRS): secondary analyses of Ontario data submitted between 1996 and 2011. BMC Med Inform Decis Mak 2013;13:27.

9. Stone NJ, Robinson JG, Lichtenstein AH, et al.; American College of Cardiology/American Heart Association Task Force on Practice Guidelines. 2013 ACC/ AHA guideline on the treatment of blood cholesterol to reduce atherosclerotic cardiovascular risk in adults: a report of the American College of Cardiology/ American Heart Association Task Force on Practice Guidelines. J Am Coll Cardiol 2014;63:2889-934.

10. Javed U, Deedwania PC, Bhatt DL, et al. Use of intensive lipid-lowering therapy in patients hospitalized with acute coronary syndrome: an analysis of 65,396 hospitalizations from 344 hospitals participating in Get With The Guidelines (GWTG). Am Heart J 2010;160:1130-6, 1136.e1-3.

11. Ko DT, Wijeysundera HC, Jackevicius CA, et al. Diabetes mellitus and cardiovascular events in older patients with myocardial infarction prescribed intensivedose and moderate-dose statins. Circ Cardiovasc Qual Outcomes 2013;6:315-22. 
12. Foebel AD, Liperoti R, Gambassi G, et al. Prevalence and correlates of cardiovascular medication use among nursing home residents with ischemic heart disease: results from the SHELTER study. J Am Med Dir Assoc 2014;15:410-5.

13. Rothschild DP, Novak E, Rich MW. Effect of statin therapy on mortality in older adults hospitalized with coronary artery disease: a propensity-adjusted analysis. J Am Geriatr Soc 2016;64:1475-9.

14. Campitelli MA, Bronskill SE, Hogan DB, et al. The prevalence and health consequences of frailty in a population-based older home care cohort: a comparison of different measures. BMC Geriatr 2016;16:133.

15. Maclagan LC, Maxwell CJ, Gandhi S, et al. Frailty and potentially inappropriate medication use at nursing home transition. J Am Geriatr Soc 2017; 65:2205-12.

16. Reid RJ, MacWilliam L, Verhulst L, et al. Performance of the ACG case-mix system in two Canadian provinces. Med Care 2001;39:86-99.

17. Austin PC. Balance diagnostics for comparing the distribution of baseline covariates between treatment groups in propensity-score matched samples. Stat Med 2009;28:3083-107.

18. Austin PC, Lee DS, Fine JP. Introduction to the analysis of survival data in the presence of competing risks. Circulation 2016;133:601-9.

19. Austin PC. The use of propensity score methods with survival or time-to-event outcomes: reporting measures of effect similar to those used in randomized experiments. Stat Med 2014;33:1242-58.

20. Vaes B, Depoortere D, Van Pottelbergh G, et al. Association between traditional cardiovascular risk factors and mortality in the oldest old: untangling the role of frailty. BMC Geriatr 2017;17:234.

21. Yan YL, Qiu B, Hu LJ, et al. Efficacy and safety evaluation of intensive statin therapy in older patients with coronary heart disease: a systematic review and meta-analysis. Eur J Clin Pharmacol 2013;69:2001-9.

22. Stroes ES, Thompson PD, Corsini A, et al.; European Atherosclerosis Society Consensus Panel. Statin-associated muscle symptoms: impact on statin therapy - European Atherosclerosis Society Consensus Panel Statement on Assessment, Aetiology and Management. Eur Heart J 2015;36:1012-22.

23. Dormuth CR, Hemmelgarn BR, Paterson JM, et al.; Canadian Network for Observational Drug Effect Studies. Use of high potency statins and rates of admission for acute kidney injury: multicenter, retrospective observational analysis of administrative databases. BMJ 2013;346:f880.

24. Hippisley-Cox J, Coupland C. Unintended effects of statins in men and women in England and Wales: population based cohort study using the QResearch database. BMJ 2010;340:c2197.

25. Wiggins BS, Saseen JJ, Page RL II, et al.; American Heart Association Clinical Pharmacology Committee of the Council on Clinical Cardiology; Council on Hypertension; Council on Quality of Care and Outcomes Research; Council on Functional Genomics and Translational Biology. Recommendations for management of clinically significant drug-drug interactions with statins and select agents used in patients with cardiovascular disease: a scientific statement from the American Heart Association. Circulation 2016;134:e468-95.

26. Strandberg TE, Kolehmainen L, Vuorio A. Evaluation and treatment of older patients with hypercholesterolemia: a clinical review. JAMA 2014;312:1136-44.

27. Danaei G, Tavakkoli M, Hernan MA. Bias in observational studies of prevalent users: lessons for comparative effectiveness research from a meta-analysis of statins. Am J Epidemiol 2012;175:250-62.

28. Tjia J, Gurwitz JH, Briesacher BA. Challenge of changing nursing home prescribing culture. Am J Geriatr Pharmacother 2012;10:37-46.

29. Tjia J, Cutrona SL, Peterson D, et al. Statin discontinuation in nursing home residents with advanced dementia. J Am Geriatr Soc 2014;62:2095-101.

30. Tjia J, Lapane K. Guideline-based prescribing in frail elderly patients. JAMA Intern Med 2017;177:262-3.

31. Ramos R, Comas-Cufi M, Marti-Lluch R, et al. Statins for primary prevention of cardiovascular events and mortality in old and very old adults with and without type 2 diabetes: retrospective cohort study. BMJ 2018;362:k3359.

\section{Competing interests: None declared.}

This article has been peer reviewed.

Affiliations: ICES (Campitelli, Maxwell, Maclagan, Ko, Bell, Daneman, Bronskill); Sunnybrook Research Institute (Ko, Daneman, Bronskill), Department of Cardiology (Ko) and Division of Infectious Diseases (Daneman), Sunnybrook Health Sciences Centre; Department of Medicine (Ko, Bell, Morris, Daneman) and Institute of Health Policy, Management and Evaluation (Ko, Jeffs, Daneman, Bronskill), University of Toronto; Lawrence S. Bloomberg Faculty of Nursing (Jeffs), University of Toronto; Division of General Internal Medicine (Bell), Mount Sinai Health System; Women's College Research Institute (Bronskill), Women's College Hospital; Keenan Research Centre at the Li Ka Shing Knowledge Institute (Jeffs), St. Michael's Hospital, Toronto, Ont.; Schools of Pharmacy (Maxwell) and Public Health and Health Systems (Maxwell), University of Waterloo, Waterloo, Ont.; Department of Quantitative Health Sciences (Lapane), University of Massachusetts Medical School, Worchester, Mass.

Contributors: Michael Campitelli, Susan Bronskill, Dennis Ko and Colleen Maxwell conceived and designed the study. Michael Campitelli carried out the statistical analy- sis. Michael Campitelli, Susan Bronskill and Colleen Maxwell drafted the manuscript. All of the authors contributed to the interpretation of data, critical revisions of the manuscript for important intellectual content, gave final approval of the version to be published and agreed to be accountable for all aspects of the work.

Funding: This research was funded in part by the Canadian Frailty Network, supported by the Government of Canada through the Networks of Centres of Excellence Program (grant no. SIG2014-M1) and also the Canadian Institutes of Health Research through operating grants MOP-136854). Dennis Ko is supported by a Mid-Career Investigator Award from the Heart and Stoke Foundation of Canada. The study sponsors provided the operating costs and infrastructure to support the research. No funding bodies had any role in the study design, data collection, analysis, decision to publish or preparation of the manuscript.

Data sharing: The data set from this study is held securely in coded form at ICES. While data-sharing agreements prohibit ICES from making the data set publicly available, access may be granted to those who meet prespecified criteria for confidential access, available at www.ices.on.ca/DAS. The full data set cre- ation plan and underlying analytic code are available from the authors upon request, understanding that the programs may rely upon coding templates and macros that are unique to ICES.

Acknowledgements: The authors thank Leah Edwards for her support in preparing the manuscript. They also thank IMS Brogan Inc. for use of their Drug Information Database.

Disclaimer: This study was supported by ICES, which is funded by an annual grant from the Ontario Ministry of Health and Long-Term Care (MOHLTC). The opinions, results and conclusions reported in this paper are those of the authors and are independent from the funding sources. No endorsement by ICES or the Ontario MOHLTC is intended or should be inferred. Parts of this material are based on data and information compiled and provided by the Canadian Institute for Health Information (CIHI). However, the analyses, conclusions, opinions and statements expressed herein are those of the author, and not necessarily those of $\mathrm{CIHI}$.

Accepted: Nov. 27, 2018

Correspondence to: Susan Bronskill, susan. bronskill@ices.on.ca 